\title{
Love styles, coping, and relationship satisfaction: A dyadic approach
}

\author{
ANA VEDES, ${ }^{a}$ PETER HILPERT, ${ }^{b}$ FRIDTJOF W. NUSSBECK, ${ }^{c}$ \\ ASHLEY K. RANDALL ${ }^{d}$ GUY BODENMANN, ${ }^{e}$ AND WOLFGANG R. LIND ${ }^{f}$ \\ ${ }^{a}$ University Children's Hospital of Zurich, Switzerland; ${ }^{b}$ University of Washington, USA; \\ ${ }^{c}$ Bielefeld University, Germany; ${ }^{d}$ Arizona State University, USA; ${ }^{e}$ University of Zurich, \\ Switzerland; and ${ }^{f}$ University of Lisbon, Portugal
}

\begin{abstract}
Romantic partners have different attitudes on what love is and what it means to be in a romantic relationship. These attitudes are conceptualized as love styles that relate to relationship-maintenance behaviors and relationship satisfaction. Specifically, love styles could be associated with how partners cope with stress (dyadic coping), which in turn may be associated with relationship satisfaction. Using self-report data from 92 heterosexual couples, findings showed that: (a) eros and agape love styles have positive direct effects on dyadic coping and relationship satisfaction, whereas ludus has a negative direct effect on dyadic coping and relationship satisfaction and (b) dyadic coping partially mediated the association between love styles and relationship satisfaction. Overall, associations were stronger for women than for men.
\end{abstract}

Love styles are the attitudes that describe how individuals define love in the context of their romantic relationship. These attitudes affect how individuals feel about and behave in their relationship (Lee, 1977; Levine, Aune, \& Park, 2006). However, research on the behavioral correlates of love styles and on mechanisms explaining its links to relationship satisfaction is still scarce. Dyadic coping-how

Ana Vedes, Department of Psychosomatic and Psychiatry, University Children's Hospital of Zurich, Switzerland; Peter Hilpert, Department of Psychiatry and Behavioral Sciences, University of Washington, USA; Fridtjof W. Nussbeck, Department of Psychology, Bielefeld University, Germany; Ashley K. Randall, Counseling and Counseling Psychology, Arizona State University, USA; Guy Bodenmann, Department of Psychology, University of Zurich, Switzerland; Wolfgang R. Lind, Department of Psychology, University of Lisbon, Portugal.

This research was supported by a doctoral grant given to the first author (AV) from the Portuguese Foundation for Science and Technology (SFRH/BD/63182/2009).

Correspondence should be addressed to Ana Vedes, Department of Psychosomatic and Psychiatry, University Children's Hospital of Zurich, Steinwiesstrasse 27, 8032 Zurich, Switzerland, e-mail: AnaMaria. VedesPacheco@kispi.uzh.ch; anavedes@gmail.com couples support each other or jointly deal with stress-is considered a critical behavioral correlate of couples' functioning (e.g., Revenson \& Lepore, 2012). Experiencing stress is inevitable for couples, and these experiences can negatively affect relationship quality (see Randall \& Bodenmann, 2009). Therefore, engaging in dyadic coping behaviors is paramount for couple's relationship satisfaction (Herzberg, 2013; Levesque, Lafontaine, Caron, Flesch, \& Bjornson, 2014), by buffering the negative impact of stress on the relationship (Falconier, Nussbeck, \& Bodenmann, 2013) and by promoting couples' sense of we-ness (Vedes, Bodenmann, Nussbeck, Randall, \& Lind, 2015).

Despite the knowledge about the importance of love styles (Hendrick \& Hendrick, 1989 ) as well as of dyadic coping (Bodenmann, Pihet, \& Kayser, 2006) for intimate relationships, there are important questions that remain unanswered. First, how is one's attitude toward love (i.e., specific love styles) associated with the way individuals support their partner and/or cope together with stress (i.e., specific dyadic 
coping behaviors)? Second, does dyadic coping mediate the association between love styles and relationship satisfaction? Answering these questions can provide relationship researchers and practitioners with additional knowledge about how to best help couples with different love styles cope with stress.

\section{Love styles}

Six love styles have been postulated in the literature emphasizing different intrinsic attitudes about love: eros, storge, agape, ludus, pragma, and mania (e.g., Hendrick \& Hendrick, 1986). Eros emphasizes beauty, strong physical attraction, emotional intensity, commitment, and seeing the lover as "the one." Storge incorporates companionship-driven love and commitment. Agape is composed of commitment and partner-centered elements of love, like giving, caring, and tolerance. Ludus frequently involves a relationship with several partners, and deception and manipulation might be accepted, whereas strong emotional connection, commitment, and jealousy are avoided. Pragma assumes compatibility and determination of future goals, and mania includes intense emotional dependency and jealousy (Hendrick \& Hendrick, 1986).

Importantly, only eros, agape, and ludus have been found to be associated with relationship satisfaction (Davis \& Latty-Mann, 1987; Hendrick, Hendrick, \& Adler, 1988; Meeks, Hendrick, \& Hendrick, 1998; Morrow, Clark, \& Brock, 1995) as well as with some relationship-maintenance behaviors (Hammock \& Richardson, 2011; Kimberly \& Werner-Wilson, 2013; Levine et al., 2006; Levy \& Davis, 1988; Richardson, Hammock, Lubben, \& Mickler, 1989). Based on these findings, we focus on eros, agape, and ludus love in the current study. Despite the evidence that endorsing eros, agape, and ludus love styles impacts the way partners generally behave in romantic relationships, research on the behavioral correlates of these love styles is limited to conflict management (Kimberly \& Werner-Wilson, 2013; Levy \& Davis, 1988), communication, showing affection, sexual activity, and seeking support and assistance (Hammock \& Richardson, 2011; Levine et al.,
2006). Thus, the associations with dyadic coping behaviors remain unexplored in the literature.

\section{Dyadic coping}

According to the systemic-transactional model (STM; Bodenmann, 1995, 2005), dyadic coping is conceptualized as a process wherein Partner A (the stressed partner) communicates his or her stress to Partner B (the nonstressed partner), and the latter reacts to the stress signals. Following this interaction, Partner B interprets the stress of Partner A, which can result in the Partner B's own stress contagion, lack of response (ignoring), or engagement in dyadic coping. Among functional forms of dyadic coping, one can differentiate between: (a) supportive dyadic coping (SDC), which happens when one partner supports the stressed partner using unidirectional emotion- or problem-focused and/or delegated dyadic coping behaviors (e.g., show empathy and understanding, analyze the situation, and do things for the partner) and (b) common dyadic coping (CDC), which happens when partners cope together with a joint stressor (e.g., parenting) by engaging in emotion and problem-focused behaviors (e.g., going for a walk together). A dysfunctional form of dyadic coping is termed negative dyadic coping, which happens when one partner provides the stressed partner using the negative support (e.g., mocking, disparaging, and ambivalent support; Bodenmann, 1995, 2005).

\section{Love styles and dyadic coping}

The initial conceptualization of the STM postulates that the performance of dyadic coping is influenced by intrapersonal determinants. However, research on why partners engage in dyadic coping remains mainly unexplored in the literature (for exceptions regarding attachment styles and relationship standards, see Gagliardi et al., 2013; Wunderer \& Schneewind, 2008, respectively). Given the fact that love styles can be considered an intrinsic determinant associated with one's behavior in the relationship (e.g., showing affection Levine et al., 2006), it is likely that 
love styles are also related to dyadic coping behaviors. As commitment is an important attitude in eros and agape, it is reasonable to assume that individuals endorsing eros or agape would show more functional forms of dyadic coping (SDC and CDC), whereas individuals higher on ludus (lack of intimacy and commitment) are expected to show less functional dyadic coping behaviors.

\section{Mediating role of dyadic coping}

To date, a dearth of research has examined mechanisms behind how love styles may affect relationship satisfaction (see Fricker \& Moore, 2002). We presume that dyadic coping behaviors are a crucial mediator explaining the association between love styles and relationship satisfaction because both love styles and dyadic coping influence relationship satisfaction (Bodenmann et al., 2006; Hendrick et al., 1988). Additionally, dyadic coping is considered a relationship-maintenance behavior (Bodenmann, 1995), which should be influenced by eros, agape, and ludus, because these love styles are associated with different relationship-maintenance behaviors (Hammock \& Richardson, 2011; Kimberly $\&$ Werner-Wilson, 2013). For instance, both eros and agape are associated with constructive approaches to conflict (i.e., integrating, obliging, and compromising; Levy \& Davis, 1988; Richardson et al., 1989), whereas ludus is associated with destructive approaches to conflict (i.e., avoiding, dominating, contempt, criticism, and stonewalling; Kimberly \& Werner-Wilson, 2013; Levy \& Davis, 1988; Richardson et al., 1989).

\section{Present study}

In the first step, we aimed to replicate prior research findings that only eros, agape, and ludus are associated with relationship satisfaction. Then, we examined the following hypotheses at a dyadic level. First, based on prior literature, we expected that eros and agape have positive direct effects on relationship satisfaction, whereas ludus would have a negative direct effect on relationship satisfaction (H1). Second, grounded on previous studies on love styles and on the STM, we expected that eros and agape would have positive direct effects on SDC and on $\mathrm{CDC}$, whereas ludus would have negative direct effects on SDC and on CDC (H2). Third, we expected that eros and agape love would have indirect positive effects on relationship satisfaction via SDC and CDC, whereas ludus would have negative indirect effects on relationship satisfaction via SDC and CDC (H3).

In addition to our within-person hypotheses (i.e., actor effects), we further expected to find partner effects in the above-mentioned hypotheses. Previous studies have shown that partners' love styles mutually influence each other (see Hendrick et al., 1988; Morrow et al., 1995). However, due to incongruent findings in this literature regarding the direction of partner effects on the associations between love styles and relationship satisfaction, we do not present any a priori hypotheses. Finally, we aimed to test whether our findings hold true when controlling for relationship length as the quality of intimate relationships tends to deteriorate over time (e.g., Umberson, Williams, Powers, Chen, $\&$ Campbell, 2005). Individuals in longer relationships may show high scores on favorable love styles and dyadic coping capacities because partners know each other to a greater extent or due to the fact that couples with low favorable love, bad dyadic coping, or low relationship satisfaction may have separated.

\section{Method}

\section{Participants}

Our sample included 92 heterosexual couples $(N=184$ individuals $)$ from the German-speaking region of Switzerland. Men's mean age was 37.5 years $(S D=10.3)$ and women's mean age was 34.7 years $(S D=10.8)$. Forty-eight percent of the couples were married and $72 \%$ of these had children $(M d n=2)$. Married couples were, on average, in a relationship for 17.2 years $(S D=9.9$, range $=2.5-35$ years $)$. Unmarried couples were, on average, in a relationship for 5.3 years $(S D=4.0$, range $=1-22$ years $)$ and had no children. All couples were cohabitating. The majority of the participants $(84 \%)$ were of Swiss nationality. Approximately 58.2\% 
of men had an annual income below 80.000 CHF (approximately US\$91,500) and 57.8\% of women had an annual income below 40.000 CHF (approximately US $\$ 45,500$ ). The majority of men $(74 \%)$ and women $(69.6 \%)$ had a basic education and no college degree. These sample demographics are representative of the Swiss population (Swiss Statistics, 2014) with a medium socioeconomic status.

\section{Procedure}

Interested couples responded to newspaper advertisements recruiting participants for a study about love, coping, and relationship satisfaction. Eligible participants had to meet the following criteria: (a) be in a heterosexual intimate relationship, (b) cohabitating for a minimum of 1 year, and (c) be at least 18 years of age. Participants contacted the research staff and, if eligible, were then mailed two sets of questionnaires including the informed consent. Participants were asked to fill in their questionnaires independently from their partner. Upon completion of the questionnaires, participants sent the questionnaires back using prepaid envelopes. Participants were not compensated for their participation.

\section{Measures}

\section{Demographics}

The demographic questionnaire included questions about age, gender, relationship status, relationship length (i.e., the time before and after marriage if married, the time being in the relationship if unmarried), number of children, nationality, income, and education level.

\section{Dyadic coping}

The Dyadic Coping Inventory (DCI; Bodenmann, 2008) is a self-report inventory of 37 items measured on a 5-point Likert scale, ranging from 1 (very rarely) to 5 (very often), and is composed of seven subscales. For our purposes, we used two aggregated scales of functional dimensions: SDC to capture individual support provision of positive dyadic coping behaviors (seven items; e.g., "I show empathy and understanding to my partner"), combined with the inverse coded items of negative behaviors (four items; e.g., "I do not take my partner's stress seriously") to cover the important aspect of providing genuine support. Additionally, we used CDC (four items; e.g., "We try to cope with the problem together and search for ascertained solutions") to capture joint supportive behaviors. The DCI subscales' reliabilities were reasonable, with Cronbach's $\alpha$ s ranging from .77 to .88 for women and .63 to .85 for men.

\section{Love styles}

The Marburg Attitude Scales toward Love Styles (MEIL; Bierhoff, Grau, \& Ludwig, 1993) is a self-report inventory of 60 items measured on a 9-point Likert scale, ranging from 1 (absolutely false) to 9 (absolutely right). This scale is the German adaptation of the Love Attitudes Scale of Hendrick and Hendrick (1986). The MEIL measures the original six styles of love, but using different names: romantic love (for eros; e.g., "I feel that my partner and I are meant for each other"), friendship love (for storge; e.g., "The best kind of love comes out of a close friendship"), altruistic love (for agape; e.g., "I would rather suffer myself than seeing my partner suffer"), ludic love (for ludus; e.g., "It is great fun for me to play the "game of love" with several partners"), pragmatic love (for pragma; e.g., "I considered what my partner is going to become in life before I enter a love relationship with him/her"), and possessive love (for mania; e.g., "If my relationship breaks up, I would feel so depressed that I could even think of suicide"). Subscales' reliabilities were reasonable, with Cronbach's $\alpha$ s ranging from .70 to .93 for women and .65 to .90 for men.

\section{Relationship satisfaction}

The Dyadic Adjustment Scale (DAS; Spanier, 1976; translated into German by Hank, Hahlweg, \& Klann, 1990) is a self-report inventory of 32 items measured on a 6-point Likert scale, ranging from 1 (always) to 6 (never). In this study, a total mean score for the DAS was computed to measure overall relationship satisfaction. This scale showed good reliability, with Cronbach's $\alpha$ s ranging from .94 for women and .91 for men. 


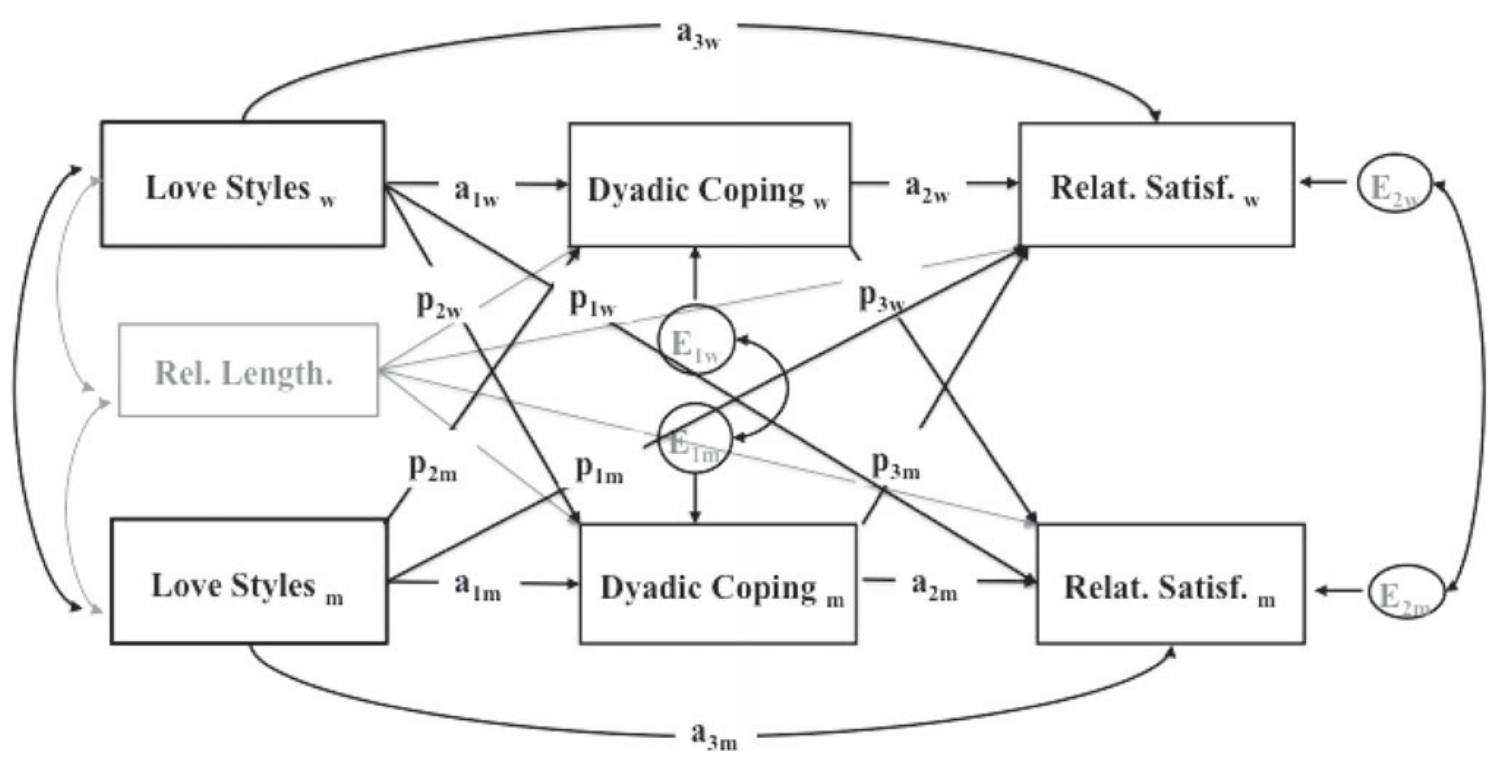

Figure 1. Actor-partner interdependence path analytical mediation model. $w=$ women; $\mathrm{m}=\mathrm{men} ; \mathrm{a}=$ actor effect; $\mathrm{p}=$ partner effect. Models were computed separately for each love style as independent variables and separately for two dyadic coping (DC) aggregated scales (supportive DC and common DC) as mediators and relationship satisfaction as criterion variable.

\section{Analytic strategy}

Correlation analysis was used to identify the bivariate associations between love styles and relationship satisfaction. When these associations were significant, the correspondent love style was then included in path analyses within the framework of actor-partner interdependence mediation models (APIMeMs; Ledermann, Macho, \& Kenny, 2011; see Figure 1) to test our hypotheses. In APIMeM, the dyad is the level of analysis: Both partners' criterion variables (relationship satisfaction) are simultaneously explained by the two predictor variables of both partners (love styles) and the two mediating variables of both partners (dyadic coping). Additionally, in APIMeM, both partners' variables can be linked to each other. Links between variables within an individual are called actor effects; links between variables across individuals are called partner effects. In order to account for the interdependence of the two partners' variables, the predictor variables, the regression residuals of the mediating, and the regression residuals of the criterion variables are allowed to covary.

Relationship length was entered as a control variable in all models. Models were run using
Mplus 7.1 (Muthén \& Muthén, 1998-2013) applying the maximum likelihood estimator. Additionally, we tested models with complete mediation, yet because these models did not fit the data, we only present results from analyses with partial mediation.

\section{Results}

\section{Preliminary analysis}

Means, standard deviations, and tests for gender differences for all study variables are shown in Table 1. Table 2 shows the intercorrelations between the study variables. As expected, only specific love styles correlated significantly with relationship satisfaction: eros, ludus, and agape. Likewise, both eros and agape were also consistently correlated with SDC and CDC for both genders, but the same association did not hold for men's ludus love. Additionally, eros and agape do correlate positively for both sexes, whereas ludus mainly correlates negatively with eros and agape; that is, individuals may score high on eros and agape simultaneously but tend to score low on ludus or vice versa. In order to avoid multicollinearity problems among mediators, we ran separate APIMeM per each dyadic coping behavior (SDC and 
Table 1. Descriptive statistics, reliabilities, and mean differences

\begin{tabular}{|c|c|c|c|c|c|c|c|}
\hline \multirow[b]{2}{*}{ Variables } & \multicolumn{3}{|c|}{ Men } & \multicolumn{3}{|c|}{ Women } & \multirow{2}{*}{$\begin{array}{l}\mathrm{W} \\
p\end{array}$} \\
\hline & $M$ & $S D$ & $\alpha$ & $M$ & $S D$ & $\alpha$ & \\
\hline Eros & 7.40 & 1.27 & .90 & 7.16 & 1.56 & .93 & .14 \\
\hline Ludus & 2.48 & 1.15 & .65 & 2.57 & 1.46 & .80 & .84 \\
\hline Storge & 5.46 & 1.58 & .78 & 5.23 & 1.60 & .83 & .24 \\
\hline Pragma & 4.36 & 1.65 & .81 & 4.48 & 1.56 & .81 & .44 \\
\hline Mania & 5.30 & 1.50 & .79 & 5.70 & 1.43 & .79 & .05 \\
\hline Agape & 7.16 & 1.17 & .84 & 6.79 & 1.29 & .87 & .03 \\
\hline Supportive DC & 3.94 & 0.51 & .81 & 4.08 & 0.57 & .86 & .03 \\
\hline Common DC & 3.61 & 0.64 & .72 & 3.60 & 0.74 & .81 & .94 \\
\hline $\mathrm{RS}$ & 3.55 & 0.51 & .91 & 3.57 & 0.59 & .94 & .49 \\
\hline
\end{tabular}

Note. $N=92$ couples. Significant $p$ values $(p \leq .05$, two-tailed) are in bold print. $\mathrm{DC}=$ dyadic coping; $\mathrm{RS}=$ relationship satisfaction; RL= relationship length; $\mathrm{W}=$ Wilcoxon signed rank test. $N=92$ couples.

Table 2. Spearman correlations of study variables

\begin{tabular}{|c|c|c|c|c|c|c|c|c|c|c|}
\hline Scales & 1 & 2 & 3 & 4 & 5 & 6 & 7 & 8 & 9 & 10 \\
\hline 1. Eros & $.68 * *$ & $-.39 * *$ & -.19 & .02 & .14 & $.44 * *$ & $.43 * *$ & $.54 * *$ & $.74 * *$ & -.19 \\
\hline 2. Ludus & $-.26^{*}$ & $.42 * *$ & .13 & .07 & .05 & $-.39 * *$ & $-.29 * *$ & $-.26^{*}$ & $-.52 * *$ & .06 \\
\hline 3. Storge & -.13 & .16 & $.40 * *$ & $.33 * *$ & -.05 & .17 & $-.26^{*}$ & -.16 & -.19 & $.22 *$ \\
\hline 4. Pragma & .01 & .14 & $.29 * *$ & $.44 * *$ & .01 & $.26^{*}$ & -.15 & -.01 & -.01 & .13 \\
\hline 5. Mania & .19 & -.15 & .12 & $.26^{*}$ & $.23 *$ & .16 & $.23 *$ & .12 & .01 & -.00 \\
\hline 6. Agape & $.60 * *$ & -.11 & .12 & .10 & $.43^{* *}$ & $.44 * *$ & $.27 * *$ & $.33 * *$ & $.41 * *$ & .02 \\
\hline 7. Supportive DC & $.36^{* *}$ & -.06 & -.17 & -.08 & -.02 & $.23 * *$ & $.22 * *$ & $.72 * *$ & $.50 * *$ & -.16 \\
\hline 8. Common DC & $.48 * *$ & -.13 & .06 & .02 & -.01 & $.33 * *$ & $.54 * *$ & $.28 * *$ & $.56^{* *}$ & $-.22 *$ \\
\hline 9. RS & $.69 * *$ & $-.31 * *$ & .04 & .09 & .15 & $.43 * *$ & $.36^{* *}$ & $.50 * *$ & $.68 * *$ & -.18 \\
\hline 10. RL & -.12 & .01 & $.25^{*}$ & .08 & .03 & .00 & -.10 & $-.22 *$ & -.20 & - \\
\hline
\end{tabular}

Note. $N=92$ couples. $\mathrm{DC}=$ dyadic coping; $\mathrm{RL}=$ relationship length; $\mathrm{RS}=$ relationship satisfaction. Cells below the diagonal indicate correlations between variables of the men's reports; cells above the diagonal indicate correlations of the women' reports; dark gray cells indicate correlations of both partners' scores representing the same constructs (within-couple correlations).

${ }^{*} p \leq .05 .{ }^{* *} p \leq .01$ (two-tailed).

$\mathrm{CDC}$ ), as strong correlations between the two dimensions were found $(r=.72$ for women and $r=.54$ for men).

\section{APIMeMs}

\section{Model 1: SDC as a mediator (Table 3)}

a. Eros. Using eros as predictor variable yields explained variances of: $R^{2}=.57$ for women's and $R^{2}=.43$ for men's relationship satisfaction; the explained variances for SDC were: $R^{2}=.26$ for women and $R^{2}=.10$ for men.

We found significant actor effects of women's eros on relationship satisfaction $(\beta=.61, p=.000)$ and of men's eros on relationship satisfaction $(\beta=.51, p=.000)$, supporting H1 (love styles explain relationship satisfaction). One actor effect of women's eros on SDC $(\beta=.55, p=.000)$ was found, partially supporting $\mathrm{H} 2$ (love styles explain dyadic coping). Indirect effects between eros and relationship satisfaction were not found for both genders not supporting $\mathrm{H} 3$ (the effect of love styles on relationship satisfaction is mediated via dyadic coping).

b. Agape. Using agape as predictor variable yields explained variances of: $R^{2}=.33$ for women's and $R^{2}=.25$ for men's relationship satisfaction; the explained variances for SDC were: $R^{2}=.13$ for women and $R^{2}=.07$ for men.

We found significant actor effects of women's agape on relationship satisfaction $(\beta=.21, p=.022)$ and of men's agape on relationship satisfaction $(\beta=.30, p=.005)$, 
Table 3. Standardized direct, indirect, total indirect, and total effects of the APIMeMs with supportive DC as mediator

\begin{tabular}{|c|c|c|c|c|c|c|c|c|c|}
\hline & \multicolumn{9}{|c|}{ Love style } \\
\hline & \multicolumn{3}{|c|}{ Eros } & \multicolumn{3}{|c|}{ Agape } & \multicolumn{3}{|c|}{ Ludus } \\
\hline & Est. & $S E$ & $p$ & Est. & $S E$ & $p$ & Est. & $S E$ & $p$ \\
\hline \multicolumn{10}{|l|}{ Actor effects } \\
\hline $\mathrm{LS}_{\mathrm{w}} \rightarrow \mathrm{RS}_{\mathrm{w}}$ & .608 & .134 & .000 & .211 & .092 & .022 & -.355 & .098 & .000 \\
\hline $\mathrm{LS}_{\mathrm{w}} \rightarrow \mathrm{SDC}_{\mathrm{w}}$ & .546 & .120 & .000 & .289 & .121 & .017 & -.336 & .101 & .001 \\
\hline $\mathrm{SDC}_{\mathrm{w}} \rightarrow \mathrm{RS}_{\mathrm{w}}^{\mathrm{w}}$ & .156 & .108 & .148 & .367 & .101 & .000 & .321 & .103 & .002 \\
\hline $\mathrm{LS}_{\mathrm{m}} \rightarrow \mathrm{RS}_{\mathrm{m}}$ & .507 & .120 & .000 & .302 & .107 & .005 & -.146 & .085 & .087 \\
\hline $\mathrm{LS}_{\mathrm{m}} \rightarrow \mathrm{SDC}_{\mathrm{m}}$ & .258 & .156 & .098 & .147 & .110 & .183 & .003 & .088 & .969 \\
\hline $\mathrm{SDC}_{\mathrm{m}} \rightarrow \mathrm{RS}_{\mathrm{m}}$ & .165 & .101 & .102 & .237 & .106 & .025 & .319 & .103 & .002 \\
\hline \multicolumn{10}{|l|}{ Partner effects } \\
\hline $\mathrm{LS}_{\mathrm{w}} \rightarrow \mathrm{RS}_{\mathrm{m}}$ & .148 & .112 & .189 & .172 & .104 & .098 & -.201 & .099 & .043 \\
\hline $\mathrm{LS}_{\mathrm{w}} \rightarrow \mathrm{SDC}_{\mathrm{m}}$ & .056 & .148 & .706 & .149 & .137 & .276 & -.036 & .110 & .742 \\
\hline $\mathrm{SDC}_{\mathrm{w}} \rightarrow \mathrm{RS}_{\mathrm{m}}$ & -.083 & .101 & .409 & .007 & .102 & .942 & .013 & .117 & .908 \\
\hline $\mathrm{LS}_{\mathrm{m}} \rightarrow \mathrm{RS}_{\mathrm{w}}$ & .060 & .119 & .613 & .121 & .089 & .171 & -.023 & .074 & .751 \\
\hline $\mathrm{LS}_{\mathrm{m}} \rightarrow \mathrm{SDC}_{\mathrm{w}}$ & -.086 & .118 & .465 & .078 & .110 & .481 & .027 & .091 & .765 \\
\hline $\mathrm{SDC}_{\mathrm{m}} \rightarrow \mathrm{RS}_{\mathrm{w}}$ & .165 & .101 & .409 & .127 & .093 & .172 & .188 & .082 & .002 \\
\hline \multicolumn{10}{|l|}{ Indirect effects } \\
\hline $\mathrm{LS}_{\mathrm{w}} \rightarrow \mathrm{SDC}_{\mathrm{w}} \rightarrow \mathrm{RS}_{\mathrm{w}}$ & .085 & .063 & .177 & .106 & .054 & .049 & -.108 & .048 & .024 \\
\hline $\mathrm{LS}_{\mathrm{w}} \rightarrow \mathrm{SDC}_{\mathrm{m}} \rightarrow \mathrm{RS}_{\mathrm{w}}$ & .004 & .012 & .701 & .019 & .020 & .341 & -.007 & .021 & .742 \\
\hline $\mathrm{LS}_{\mathrm{m}} \rightarrow \mathrm{SDC}_{\mathrm{m}} \rightarrow \mathrm{RS}_{\mathrm{m}}$ & .042 & .036 & .242 & .035 & .030 & .244 & .000 & .004 & .917 \\
\hline $\mathrm{LS}_{\mathrm{m}} \rightarrow \mathrm{SDC}_{\mathrm{w}} \rightarrow \mathrm{RS}_{\mathrm{m}}$ & .007 & .013 & .587 & .001 & .008 & .943 & .001 & .028 & .968 \\
\hline \multicolumn{10}{|l|}{ Total effects } \\
\hline Total effect $\mathrm{LS}_{\mathrm{w}} \rightarrow \mathrm{RS}_{\mathrm{w}}$ & .698 & .108 & .000 & .336 & .110 & .002 & -.470 & .105 & .000 \\
\hline Total effect $\mathrm{LS}_{\mathrm{m}} \rightarrow \mathrm{RS}_{\mathrm{m}}$ & .557 & .125 & .000 & .338 & .110 & .002 & -.145 & .094 & .124 \\
\hline$R^{2} \mathrm{SDC}_{\mathrm{w}}$ & .26 & & & .13 & & & .14 & & \\
\hline$R^{2} \mathrm{SDC}_{\mathrm{m}}$ & .10 & & & .07 & & & .01 & & \\
\hline$R^{2} \mathrm{RS}_{\mathrm{w}}$ & .57 & & & .33 & & & .39 & & \\
\hline$R^{2} \mathrm{RS}_{\mathrm{m}}$ & .43 & & & .25 & & & .20 & & \\
\hline
\end{tabular}

Note. APIMeMs = actor-partner interdependence mediation models; DC = dyadic coping; LS = love style (eros, agape, ludus as depicted in the headers of the columns); SDC = supportive dyadic coping; RS= relationship satisfaction; $\mathrm{w}=$ women $; \mathrm{m}=$ men; Est. = estimate; $S E=$ standard error $p=p$ value (two-tailed) $R^{2}=$ explained variance. Significant $p$ values $(p<.05)$ are in bold print. Marginal significant $p$ values $(.05<p<.10)$ are in gray bold cells.

supporting H1. Additionally, a marginal partner effect of women's agape on men's relationship satisfaction $(\beta=.17, p=.098)$ was found. One actor effect of women's agape on women's SDC $(\beta=.29, p=.017)$ was found, partially supporting H2. For women, an indirect actor effect of agape on relationship satisfaction $(\beta=.11, p=.054)$ was found, partially supporting $\mathrm{H} 3$.

c. Ludus. Using ludus as predictor variable yields explained variances of: $R^{2}=.39$ for women's and $R^{2}=.20$ for men's relationship satisfaction; the explained variances for SDC were: $R^{2}=.14$ for women and $R^{2}=.01$ for men.

We found significant actor effects of women's ludus on relationship satisfaction $(\beta=-.36, p=.000)$ and one marginal actor effect of men's ludus on relationship satisfaction $(\beta=-.15, p=.087)$, partially supporting H1. Additionally, a partner effect of women's ludus on men's relationship satisfaction $(\beta=-.20, p=.043)$ was found. An actor effect of women's ludus on SDC $(\beta=-.34$, 
Table 4. Standardized direct, indirect, total indirect, and total effects of the APIMeMs with common DC as mediator

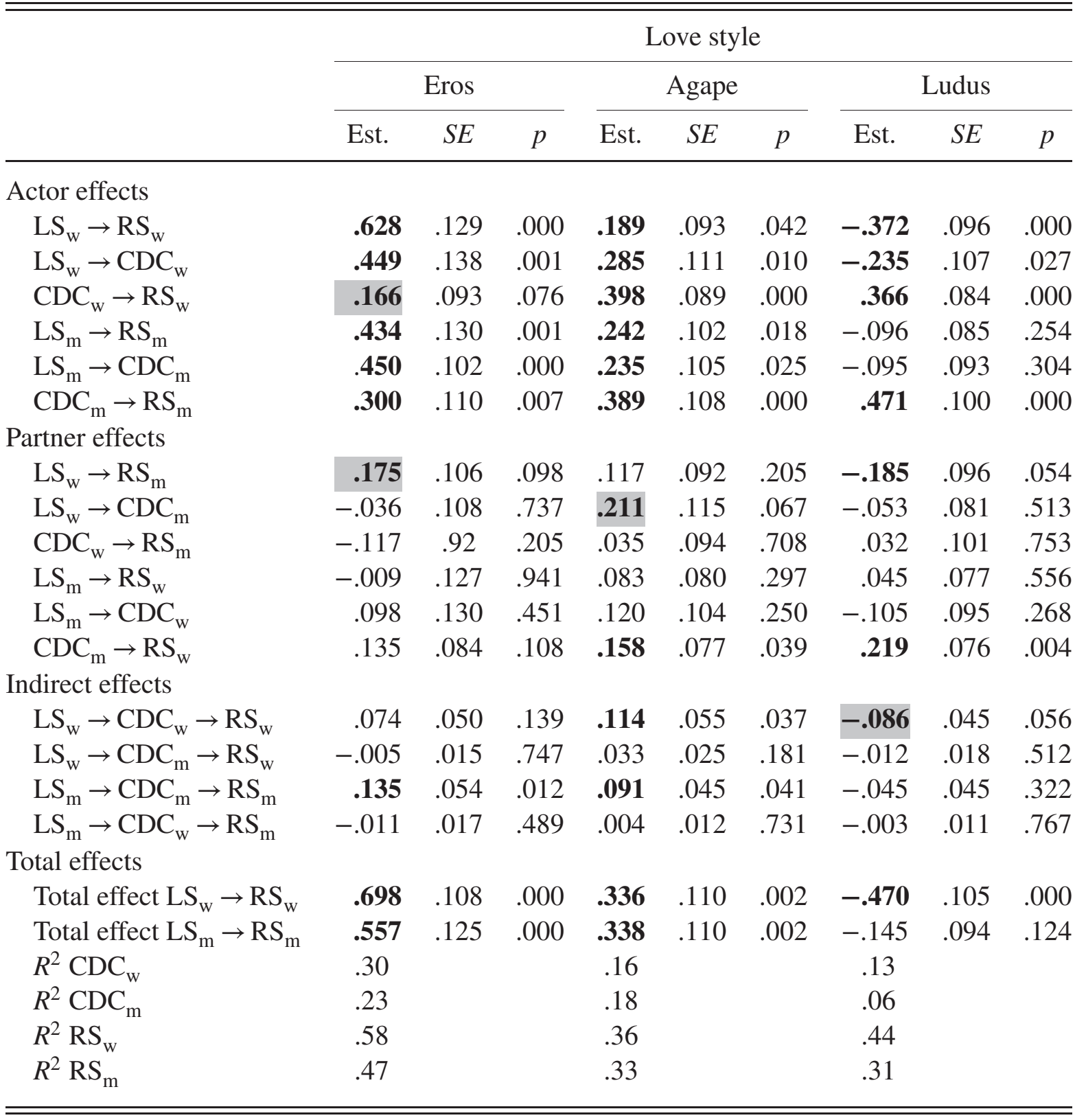

Note. APIMeMs = actor - partner interdependence mediation models; DC = dyadic coping; LS = love style (eros, agape, ludus as depicted in the headers of the columns); $\mathrm{CDC}=$ common dyadic coping; $\mathrm{RS}=$ relationship satisfaction; $\mathrm{w}=$ women; $\mathrm{m}=$ men; Est. = estimate; $S E=$ standard error; $p=p$ value (two-tailed); $R^{2}=$ explained variance. Significant $p$ values $(p<.05)$ are in bold print. Marginal significant $p$ values $(.05<p<.10)$ are in gray bold cells.

$p=.001)$ was found, partially supporting $\mathrm{H} 2$. For women, an indirect actor effect of ludus on relationship satisfaction $(\beta=-.11, p=.024)$ was found, partially supporting $\mathrm{H} 3$.

2. Model 2: CDC as a mediator (Table 4)

a. Eros. Using eros as predictor variable yields explained variances of: $R^{2}=.58$ for women's and $R^{2}=.47$ for men's relationship satisfaction; the explained variances for
CDC were: $R^{2}=.30$ for women and $R^{2}=.23$ for men.

We found significant actor effects of women's eros on relationship satisfaction $(\beta=.63, p=.000)$ and of men's eros on relationship satisfaction $(\beta=.43, p=.001)$, supporting H1. Actor effects of women's eros on women's $\mathrm{CDC}(\beta=.50, p=.001)$ and of men's eros on CDC $(\beta=.30, p=.007)$ were also found supporting $\mathrm{H} 2$. For men, an indirect 
actor effect of eros on relationship satisfaction $(\beta=.14, p=.012)$ was found, partially supporting $\mathrm{H} 3$.

b. Agape. Using agape as predictor variable yields explained variances of: $R^{2}=.36$ for women's and $R^{2}=.33$ for men's relationship satisfaction; the explained variances for CDC were: $R^{2}=.16$ for women and $R^{2}=.18$ for men.

We found significant actor effects of women's agape on relationship satisfaction $(\beta=.19, p=.042)$ and of men's agape on relationship satisfaction $(\beta=.24, p=.018)$, supporting H1. Actor effects of women's agape on CDC $(\beta=.29, p=.010)$ and of men's agape on $\operatorname{CDC}(\beta=.24, p=.018)$ were found, supporting H2. Furthermore, a marginal partner effect of women's agape on men's CDC $(\beta=.21, p=.067)$ was found. One partner effect of men's CDC on women's relationship satisfaction $(\beta=.16, p=.039)$ was also found. Indirect actor effects were found for (a) women's agape on relationship satisfaction $(\beta=.11, p=.037)$ and (b) men's agape on relationship satisfaction $(\beta=.09, p=.041)$, supporting H3.

c. Ludus. Using ludus as predictor variable yields explained variances of: $R^{2}=.44$ for women's and $R^{2}=.31$ for men's relationship satisfaction; the explained variances for CDC were: $R^{2}=.14$ for women and $R^{2}=.06$ for men.

We found a significant actor effect of women's ludus on relationship satisfaction $(\beta=-.37, p=.000)$ and a partner effect of women's ludus on men's relationship satisfaction $(\beta=-.19, p=.054)$, partially supporting H1. An actor effect of women's ludus on women's CDC ( $\beta=-.24, p=.027)$ was found, partially supporting $\mathrm{H} 2$. A partner effect of men's CDC on women's relationship satisfaction $(\beta=.22, p=.004)$ was also found. For women, a marginal indirect actor effect of ludus on relationship satisfaction $(\beta=-.09$, $p=.056$ ) was found, partially supporting H3.

\section{Discussion}

Previous research has shown that eros and agape love styles (Hendrick \& Hendrick, 2006), and functional dyadic coping behaviors
(Bodenmann et al., 2006) are positively related to relationship satisfaction, whereas the latter is negatively related to ludic love style and dysfunctional dyadic coping. However, until now, research has been scarce on why individuals engage in dyadic coping, and the behavioral mechanisms associated with how individual love attitudes are associated with relationship satisfaction. The goal of our study was to address these questions by examining the associations between love styles and dyadic coping, by specifically considering dyadic coping as a mediator between love styles and relationship satisfaction. We focused on eros, agape, and ludus love styles as their association to relationship satisfaction have received previous robust empirical support (e.g., Morrow et al., 1995). Overall, our hypotheses were supported, albeit most strongly and consistently for women.

\section{Actor effects}

\section{Total effects}

Comparing intraindividual (actor) total effects of the different love styles, our results show that individuals scoring higher on eros and agape love styles are more satisfied with their relationship. Those scoring higher in ludus are less satisfied with their relationship. This finding holds for SDC and CDC. Strongest effects can be found for eros, with a total effect of $\beta=.698$ on relationship satisfaction for women and $\beta=.557$ for men (irrespective if SDC and CDC functions as mediator). The total effect of ludus on relationship satisfaction is the second strongest for women $(\beta=-.470)$ but not for men $(\beta=-.145, n s)$. The total effects of agape on relationship satisfaction is the smallest for women $(\beta=.336)$ and the second largest for men $(\beta=.338)$. Overall, these effects can be considered substantial.

\section{Direct effects}

For both partners, we find direct actor effects on relationship satisfaction for eros and agape. The effects are strong for eros (women: $\beta=.608$ for SDC and $\beta=.628$ for CDC; men: $\beta=.507$ and $\beta=.434)$ and of medium size for agape (women: $\beta=.211$ and $\beta=.189$; men: 
$\beta=.302$ and $\beta=.242$ ). Ludus only exerts a negative effect on relationship satisfaction for women $(\beta=-.355$ and $\beta=-.372)$.

The love styles also affect SDC and CDC. Again, reliable effects can be found but mostly for women. That is, we consistently find positive effects of eros and agape and negative effects of ludus on both, provision of support to the partner and CDC, with medium to large effect sizes for women (all absolute $\beta \mathrm{s}>$.235). For men, we do not find any direct effect of love styles on SDC. Considering CDC, we find positive medium to large effects for eros $(\beta=.450)$ and agape $(\beta=.235)$ but no effect for ludus.

The pattern of direct effects of SDC and $\mathrm{CDC}$ on relationship satisfaction is less clear. Considering SDC, we find medium to large effects for agape and ludus but only for women ( $\beta=.367$ and $\beta=.321$, respectively). Considering CDC, we find medium to large effects for agape and ludus for both sexes on relationship satisfaction (women: $\beta=.398$ and $\beta=.366$; men: $\beta=.389$ and $\beta=.471$; for agape and ludus, respectively) and a medium effect for men considering eros $(\beta=.300)$.

Globally, eros, agape, and ludus appear to be mostly important when explaining dyadic coping and relationship satisfaction for women (i.e., higher explained variance, more significant actor direct, and total effects were found for women than for men). Our findings are in line with research that suggests that women tend to be more relationship oriented than men (see Cross, Bacon, \& Morris, 2000). For example, women tend to think (Sullivan \& Baucom, 2005) and talk (Acitelli, 1992) more about relationships and are usually more responsible for managing the relationship (Acitelli, Rogers, \& Knee, 1999), compared to men.

Concerning associations between ludus, dyadic coping, and relationship satisfaction, our study shows gender differences. Although previous studies have shown negative associations between women's and men's ludus and relationship-maintenance behaviors, as well as with their relationship satisfaction (e.g., Goodboy \& Myers, 2010; Hendrick et al., 1988; Morrow et al., 1995), in our study these findings did not yield for men. A convincing explanation for why ludus is significantly detrimental for women's dyadic coping and relationship satisfaction, whereas it is not related to men's dyadic coping behaviors and relationship satisfaction, is difficult to find. An explanation might be that ludus attitudes are still more socially acceptable and normal for and by men than women. These distinct social expectations and potential related pressures (e.g., from friends, colleagues, media, etc.) may differently impact within-person as well as between-partner processes even if women and men endorse similar ludus attitudes (at the mean level). Further research is needed to both replicate these findings and test this speculative explanation, while controlling for social desirability effects. The relevance of agape on dyadic coping and relationship satisfaction adds support to a relevant and relatively new area of research about agape or compassionate love, which may be regarded as cousin concepts, in close relationships (for an overview, see Fehr \& Sprecher, 2013). Our findings align with previous studies showing that compassionate love attitudes are associated with provision of social support (e.g., Collins et al., 2014) and, indirectly, that wives' compassionate love is a longitudinal predictor of the likelihood for divorce 4 years later (Neff \& Karney, 2005, 2009).

\section{Indirect effects}

Considering SDC, we only find two significant indirect actor effects for women (agape: $\beta=.106$; ludus: $\beta=-.108$ ). Considering CDC, we find three indirect actor effects (women, agape: $\beta=.114$; men, eros: $\beta=.135$; men, agape: $\beta=.091$ ). Hence, love styles appear to have different indirect effects on women's and men's relationship satisfaction. For women, high agape and low ludus promote both high provision of support to their stressed partners and high conjoint coping efforts against stress, which subsequently increases their relationship satisfaction. For men, high eros and agape only foster high conjoint coping efforts against stress, which consequently increases their satisfaction with the relationship. Contrary to our hypotheses, these love styles do not indirectly affect men's relationship satisfaction by fostering high provision of support to their partners. Also contrary to our hypothesis, the 
association between men's ludus and their relationship satisfaction was not mediated. This latter finding aligns with our previously mentioned results, which generally showed no effects of ludus love style on men's dyadic coping and relationship satisfaction. Although our study suggests that dyadic coping behaviors are more relevant mediating mechanisms for women than for men (which can be explained by women's high relational orientation; see explanation above), for both genders, CDC is slightly more important for their relationship satisfaction. This finding supports previous studies that showed CDC to be more crucial to relational and well-being outcomes above other forms of coping (e.g., Falconier et al., 2013; Kayser, Watson, \& Andrade, 2007).

\section{Partner effects}

Our results yield five small to medium partner effects, which support the call for dyadic analysis when studying love in couples (Felmlee \& Sprecher, 2006). Specifically, we found two partner effects for men such that their relationship satisfaction can be explained by their partner's ludus $(\beta=-.201$ for SDC and $\beta=-.185$ for CDC as mediators) and three partner effects for women explaining their relationship satisfaction by maintenance behaviors (models with ludus: $\beta=.188$ for SDC and $\beta=.219$ for CDC; models with agape: $\beta=.158$ for CDC). These findings partly support previous results reported by Hendrick et al. (1988), who found partners' love scores to be related to men's relationship satisfaction but not to women's, but do not support findings from Morrow et al. (1995), who found partners' love scores to be related to women's relationship satisfaction but not to men's. As the sample in both studies consisted of college students, future research is needed in order to understand older committed couples. Despite this, these findings again support the reasoning that if women are more relationship oriented, their love styles should be more relevant, not only for their own but as well as for their partners' relationship satisfaction, than men's love styles (Hendrick et al., 1988). Likewise, the partner effects found for women align with previous research, which has shown that when men adopt relationship-oriented behaviors women are happier (Acitelli, 1992; Acitelli et al., 1999; Sullivan \& Baucom, 2005).

\section{Relationship length}

Controlling for relationship length affected our results to a small extent. While our findings held for the associations between eros, agape, and ludus and relationship satisfaction, some results were found between love styles and CDC. Specifically, eros is beneficial for partner's CDC to endure over time, which can be explained with the strong emotional component of eros (Hendrick \& Hendrick, 2006). This emotional load might then function as a motivational (Noller, 2013) or commitment-related device for relationship-maintenance behaviors such as dyadic coping (cf. Fletcher, Simpson, Campbell, \& Overall, 2013; Gonzaga, Turner, Keltner, Campos, \& Altemus, 2006). For agape, CDC was slightly lower for both partners the longer the relationship. This might be due to issues of equity and fairness. In the beginning of a relationship, both partners usually and easily behave communally and mutually care for each other's needs (Clark \& Monin, 2006), but when facing increased conflict and stress, partners may start calculating fairness and equity (Grote \& Clark, 2001). Future research is needed on the association between stress, agape, dyadic coping, and relationship satisfaction, as equity and fairness issues are similarly important in the context of support provision and dyadic coping (Bodenmann, 2005; Iida, Seidman, Shrout, Fujita, \& Bolger, 2008), and for the longevity of these relationships (Berscheid, 2010; Fehr \& Sprecher, 2013; Iida et al., 2008). Interestingly, our findings also held for ludus love and relationship satisfaction. This might be due to the fact that in our sample, couples, on average, scored very low on ludus with small variance, which might have compromised the capacity of detecting significant effects. However, when couples endorsed ludus, CDC was lower for both partners the longer the relationship. This finding hints at the detrimental role that this love style has on relationship-maintenance behaviors 
(e.g., Hammock \& Richardson, 2011; Levine et al., 2006; Richardson et al., 1989).

\section{Limitations}

Although our study provides the first empirical support for the associations between love styles, dyadic coping, and relationship satisfaction, several limitations should be noted. First, our results were based on cross-sectional self-report measures, which did not allow us to make inferential conclusions or control for shared method variance. While we assume that partners first develop love styles, which then influence their dyadic coping, we cannot rule out bidirectional or even opposite effects. Second, as dyadic coping involves couples' dealing with stressful experiences, our study would have benefited from directly measuring stress (e.g., work-related stress, daily hassles). Third, we were unable to analyze all our variables together in one model or to combine profiles of love styles with the APIMeM, that is, rather use individual's profiles of love styles as predictors instead of single love styles. Fourth, our sample included couples that were generally satisfied with their relationship; therefore, generalizing these findings to other samples is difficult. Future research should take into consideration the longitudinal course of different types of love (e.g., Berscheid, 2010; Lee, 1977) and other dyadic (e.g., different life stages) and contextual (e.g., culture) variables when examining the interplay between love styles, dyadic coping, and relationship satisfaction. As such, incorporating multimethods such as observational coding may be required to gain a more nuanced picture of the rich and multidimensional phenomena like love, as well as to analyze the plausibility and implications of having a combination of several love styles, within and between couples.

\section{Conclusions and implications}

Our study makes an important contribution to the scarce knowledge of (self-reported) behavioral correlates of love and provides evidence for one factor that may explain why individuals engage in positive provision of SDC and CDC: partners' love styles, which provide empirical evidence that expands Bodenmann's (1995, 2005) STM of dyadic coping. Second, our study showed that one way how love styles are associated with relationship satisfaction may be partially through dyadic coping behaviors. Therefore, integrating the important role of both love attitudes and dyadic coping in a theoretical model as well as on interventions appears a promising way to better help couples coping with stressors while fostering a positive evaluation of their relationship.

Given the staggering rates of divorce across the world, exploring the question "How do you love me?" instead of "How much do you love me?" (Neff \& Karney, 2009) might be a key question for practitioners working in both a preventive and clinical setting to ask and analyze with their clients. Our findings suggest that partners can be satisfied and cope better with stress in their relationship by endorsing eros or agape love attitudes. Furthermore, our study identified CDC as the more important mediating coping mechanism as compared to one's unidirectional provision of dyadic coping, explaining the association between love styles and relationship satisfaction for both genders. Thus, practitioners may utilize approaches that focus on coping (e.g., Couple Coping Enhancement Training; Bodenmann \& Shantinath, 2004; Couples Coping-Oriented Therapy; Bodenmann, 2010) to help couples. By creating a space of interpersonal processing of how each partner's love attitudes affect the other and the relationship as well as by promoting dyadic coping skills, especially partners' joint strategies, could be crucial to intervene with couples dealing with stressful situations and adversities. In addition, as actor effects were strongest, individual interventions approaching one's own love attitudes can be equally important and meaningful because it is often difficult to engage both partners in therapy.

\section{References}

Acitelli, L. K. (1992). Gender differences in relationship awareness and marital satisfaction among young married couples. Personality and Social Psychology Bulletin, 18, 102-110.

Acitelli, L. K., Rogers, S., \& Knee, C. R. (1999). The role of identity in the link between relationship thinking 
and relationship satisfaction. Journal of Social and Personal Relationships, 16, 591-618.

Berscheid, E. (2010). Love in the fourth dimension. Annual Review of Psychology, 61, 1-25.

Bierhoff, H. W., Grau, I., \& Ludwig, A. (1993). Marburger Einstellungs-Inventar für Liebesstile [Marburg Attitude Scales towards Love Styles]. Göttingen, Germany: Hogrefe.

Bodenmann, G. (1995). A systemic-transactional conceptualization of stress and coping in couples. Swiss Journal of Psychology, 54, 34-49.

Bodenmann, G. (2005). Dyadic coping and its significance for marital functioning. In T. Revenson, $\mathrm{K}$. Kayser, \& G. Bodenmann (Eds.), Couples coping with stress: Emerging perspectives on dyadic coping (pp. 33-50). Washington, DC: American Psychological Association.

Bodenmann, G. (2008). Dyadisches Coping Inventar manual [Dyadic Coping Inventory manual]. Bern, Switzerland: Huber.

Bodenmann, G. (2010). New themes in couple therapy: The role of stress, coping and social support. In K. Hahlweg, M. Grawe, \& D. H. Baucom (Eds.), Enhancing couples: The shape of couple therapy to come (pp. 142-156). Cambridge, MA: Hogrefe.

Bodenmann, G., Pihet, S., \& Kayser, K. (2006). The relationship between dyadic coping, marital quality and well-being: A two year longitudinal study. Journal of Family Psychology, 20, 485-493.

Bodenmann, G., \& Shantinath, S. D. (2004). The Couples Coping Enhancement Training (CCET): A new approach to prevention of marital distress based upon stress and coping. Family Relations, 53, 477-484.

Clark, M. S., \& Monin, J. K. (2006). Giving and receiving communal responsiveness as love. In R. Sternberg \& K. Weis (Eds.), The new psychology of love (pp. 200-221). New Haven, CT: Yale University Press.

Collins, N. L., Kane, H. S., Metz, M. A., Cleveland, C., Khan, C., Winczewski, L., ... Prok, T. (2014). Psychological, physiological, and behavioral responses to a partner in need: The role of compassionate love. Journal of Social and Personal Relationships, 21, 1-29.

Cross, S. E., Bacon, P. L., \& Morris, M. L. (2000). The relational-interdependent self-construal and relationships. Journal of Personality and Social Psychology, 78, 791-808.

Davis, K. E., \& Latty-Mann, H. (1987). Love styles and relationship quality: A contribution to validation. Journal of Social and Personal Relationships, 4, 409-428.

Falconier, M. K., Nussbeck, F., \& Bodenmann, G. (2013). Immigration stress and relationship satisfaction in Latino couples: The role of dyadic coping. Journal of Social and Clinical Psychology, 32, 813-843.

Fehr, B., \& Sprecher, S. (2013). Compassionate love: What we know so far. In M. Hojjat \& D. Cramer (Eds.), Positive psychology of love (pp. 106-120). New York, NY: Oxford University Press.

Felmlee, D., \& Sprecher, S. (2006). Love: Psychological and sociological perspectives. In J. E. Stets \& J. H. Turner (Eds.), Handbook of sociology of emotions (pp. 389-409). New York, NY: Springer.
Fletcher, G., Simpson, J. A., Campbell, L., \& Overall, N. (2013). The science of intimate relationships. West Sussex, England: Wiley-Blackwell.

Fricker, J., \& Moore, S. (2002). Relationship satisfaction: The role of love styles and attachment styles. Current Research in Social Psychology, 7, 182-205.

Gagliardi, S., Bodenmann, G., Heinrichs, N., Maria Bertoni, A., Iafrate, R., \& Donato, S. (2013). Unterschiede in der Partnerschaftsqualität und im dyadischen Coping bei verschiedenen bindungsbezogenen Paartypen [Differences in relationship quality and dyadic coping for attachment-related couple types]. Psychotherapie, Psychosomatik, Medizinische Psychologie, 63, 185-192.

Gonzaga, G. C., Turner, R. A., Keltner, D., Campos, B., \& Altemus, M. (2006). Romantic love and sexual desire in close relationships. Emotion, 6, 163-179.

Goodboy, A. K., \& Myers, S. A. (2010). Relational quality indicators and love styles as predictors of negative relational maintenance behaviors in romantic relationships. Communication Reports, 23, 65-78.

Grote, N. K., \& Clark, M. S. (2001). Perceiving unfairness in the family: Cause or consequence of marital distress? Journal of Personality and Social Psychology, 2, 281-293.

Hammock, G., \& Richardson, D. S. (2011). Love attitudes and relationship experience. Journal of Social Psychology, 151, 608-624.

Hank, G., Hahlweg, K., \& Klann, N. (1990). Diagnostische Verfahren für Berater. Materialien zur Diagnostik und Therapie in Ehe-, Familien- und Lebensberatung [Diagnostic procedures for consultants. Materials for diagnosis and therapy in marriage, family and life counseling]. Weinheim, Germany: Beltz Test.

Hendrick, C., \& Hendrick, S. (1986). A theory and method of love. Journal of Personality and Social Psychology, $50,392-402$.

Hendrick, C., \& Hendrick, S. S. (1989). Research on love: Does it measure up? Journal of Personality and Social Psychology, 56, 784-794.

Hendrick, C., \& Hendrick, S. (2006). Styles of romantic love. In R. Sternberg \& K. Weis (Eds.), The new psychology of love (pp. 149-170). New Haven, CT: Yale University Press.

Hendrick, S. S., Hendrick, C., \& Adler, N. L. (1988). Romantic relationships: Love, satisfaction, and staying together. Journal of Personality and Social Psychology, 54, 980-988.

Herzberg, P. Y. (2013). Coping in relationships: The interplay between individual and dyadic coping. Anxiety, Stress and Coping: An International Journal, 26, 136-153.

Iida, M., Seidman, G., Shrout, P. E., Fujita, K., \& Bolger, N. (2008). Modeling support provision in intimate relationships. Journal of Personality and Social Psychology, 94, 460-478.

Kayser, K., Watson, L. E., \& Andrade, J. T. (2007). Cancer as a "we-disease": Examining the process of coping from a relational perspective. Families, Systems \& Health, 25, 404-418. 
Kimberly, C., \& Werner-Wilson, R. (2013). From John Lee to John Gottman: Recognizing intra- and interpersonal differences to promote marital satisfaction. Journal of Human Sciences and Extension, 1, 32-46.

Ledermann, T., Macho, S., \& Kenny, D. A. (2011). Assessing mediation in dyadic data using the actor-partner interdependence model. Structural Equation Modeling: A Multidisciplinary Journal, 18, 595-612.

Lee, J. A. (1977). A typology of styles of loving. Personality and Social Psychology Bulletin, 3, 173-182.

Levesque, C., Lafontaine, M. F., Caron, A., Flesch, J. L., \& Bjornson, S. (2014). Dyadic empathy, dyadic coping, and relationship satisfaction: A dyadic model. Europe's Journal of Psychology, 10, 118-134.

Levine, T. R., Aune, K. S., \& Park, H. S. (2006). Love styles and communication in relationships: Partner preferences, initiation, and intensification. Communication Quarterly, 54, 465-486.

Levy, M. B., \& Davis, K. E. (1988). Love styles and attachment styles compared: Their relations to each other and to various relationship characteristics. Journal of Social and Personal Relationships, 5, 439-471.

Meeks, B. S., Hendrick, S. S., \& Hendrick, C. (1998). Communication, love and relationship satisfaction. Journal of Social and Personal Relationships, 15, $755-773$.

Morrow, G. D., Clark, E. M., \& Brock, K. F. (1995). Individual and partner love styles: Implications for the quality of romantic involvements. Journal of Social and Personal Relationships, 12, 363-387.

Muthén, L. K., \& Muthén, B. O. (1998-2013). Mplus user's guide (6th ed.). Los Angeles, CA: Muthén \& Muthén.

Neff, L. A., \& Karney, B. R. (2005). To know you is to love you: The implications of global adoration and specific accuracy for marital relationships. Journal of Personality and Social Psychology, 3, 480-497.

Neff, L. A., \& Karney, B. R. (2009). Compassionate love in early marriage. In B. Fehr, S. Sprecher,
\& L. Underwood (Eds.), The science of compassionate love: Theory, research, and applications (pp. 201-222). West Sussex, England: Wiley-Blackwell.

Noller, P. (2013). Foreword. In M. Hojjat \& D. Cramer (Eds.), Positive psychology of love (pp. 106-120). New York, NY: Oxford University Press.

Randall, A. K., \& Bodenmann, G. (2009). The role of stress on close relationships and marital satisfaction. Clinical Psychology Review, 29, 105-115.

Revenson, T. A., \& Lepore, S. J. (2012). Coping in social context. In A. Baum, T. A. Revenson, \& J. E. Singer (Eds.), Handbook of health psychology (2nd ed., pp. 193-217). New York, NY: Psychology Press.

Richardson, D. R., Hammock, G. S., Lubben, T., \& Mickler, S. (1989). The relationship between love attitudes and conflict responses. Journal of Social and Clinical Psychology, 8, 430-441.

Spanier, G. B. (1976). Measuring dyadic adjustment: New scales for assessing the quality of marriage and similar dyads. Journal of Marriage and the Family, 38, 15-28.

Sullivan, L. J., \& Baucom, D. H. (2005). Observational coding of relationship-schematic processing. Journal of Marital and Family Therapy, 31, 31-43.

Swiss Statistics. (2014). Wages and income from employment-Indicators. Retrieved from http://www. bfs.admin.ch/bfs/portal/en/index/themen/01.html

Umberson, D., Williams, K., Powers, D., Chen, M. D., \& Campbell, A. (2005). As good as it gets? A life course perspective on marital quality. Social Forces, 84, 493-511.

Vedes, A., Bodenmann, G., Nussbeck, F. W., Randall, A., \& Lind, W. (2015). The role of we-ness in mediating the association between dyadic coping and relationship satisfaction. Manuscript submitted for publication.

Wunderer, E., \& Schneewind, K. A. (2008). The relationship between marital standards, dyadic coping and marital satisfaction. European Journal of Social Psychology, 38, 462-476. 